\title{
SIIRTYMÄ AIKUISUUTEEN EUROOPPALAISESSA KONTEKSTISSA ${ }^{1}$
}

Henna Isoniemi: VTT, yliopisto-opettaja, Sosiaalitieteiden laitos, Turun yliopisto

benna.isoniemi@utu.fi

Janus vol. 26 (2) 2018, 164-171

Muutin pois lapsuudenkodistani, kun oli 21-vuotias. Ensimmäinen oma asuntoni oli pieni vuokrayksiö, mutta se riitti minulle hyvin, muutinhan asumaan yksin. Olin ollut kaveriporukkani viimeinen kotonaasuja, muut olivat muuttaneet omilleen jo vuoden, kaksi aiemmin. Syy kotoa poismunttoon oli, että aloitin yliopisto-opinnot. Rahoitin opintojani suomalaiseen tapaan opintotuilla, mutta eihän ne 1990-luvullakaan mihinkään riittäneet. Kävin siis opintojeni ohessa myös töissä. Noudatin kuitenkin yliopiston suosituksia sen suhteen, että opintoni edistyivät tavoitevauhtia.

Kun olin 25-vuotias ja opintoni olivat loppuvaiheessa, tapasin tulevan aviomieheni. Suhde eteni nopeasti, elimme vain hetken elämänvaihetta, jossa seurustelimme ja asuimme erilleen. Niinpä jo 26-vuotiaana elin avoliitossa, mutta sen lisäksi olin valtiotieteiden maisteri, töissä koulutustani vastaavissa töissä ja suuruudeltaan maltillisen asuntolainan haltija. Naimisiin menimme, kun olin 30 vuotta, ja viittä vuotta myöhemmin syntyi poikamme.

Milloin minusta sitten tuli aikuinen? Tai ennemmin, mikä edellä kuvaamistani elämänmuutoksista teki minusta aikuisen? Näin jälkikäteen katsottuna sanoisin, että kotoa poismuutto oli keskeisin siirtymä omalla kohdallani. Kjell Westö (2009) tulkitsee asian samoin romaanissaan "Älä käy yöhön yksin". Hän kirjoittaa: "Kun Jouni kir- joittautui Helsingin yliopiston valtiotieteelliseen tiedekuntaan syyskuussa 1965, 19-vuotiaana, hän oli hyväksytyistä neljänneksi paras. Hän oli ollut oman itsensä herra jo kauan, ja hän onnitteli itseään siitä, että eli kuin aikamies, kun taas Ariel ja Adriana asuivat lapsuudenkodissaan vaikka olivatkin vanhempia kuin hän."

Väitöstutkimukseni mukaan minun ja Jounin kanssa samaan ajattelumalliin ovat taipuvaisia myös muut suomalaiset vielä 2000-luvullakin: keskeisimpänä aikuistumisen merkkinä suomalaiset nuoret aikuiset pitävät juuri muuttoa pois lapsuudenkodista. Ruotsalaiset, norjalaiset ja hollantilaiset nuoret aikuiset näkevät asian samoin, kun taas esimerkiksi irlantilaisille ja briteille kokoaikatyö merkitsee selvemmin aikuisuutta. Erot Euroopan maiden välillä ovat selkeät; toisissa maissa nousi selkeästi yksi siirtymä, joka määritti aikuisuuteen siirtymistä, kun taas toisissa maissa keskeisiä aikuisuutta määritteleviä tekijöitä oli kolme tai neljäkin. Näissä maissa, kuten esimerkiksi Portugalissa ja Bulgariassa, aikuisuutta määrittävät keskeisesti kaikki neljä demografista siirtymää: lapsuudenkodista poismuutto, kokoaikatyö, puolison kanssa asuminen ja vanhemmaksi tuleminen. Maiden välisistä eroista huolimatta tiettyjä maaryhmittymiä, jotka eivät kuitenkaan muistuttaneet täysin perinteisiä hyvinvointivaltioregiimejä 
(Esping-Andersen 1990; ks. myös esim. Bambra 2007), oli mahdollista muodostaa.

On varmasti aiheellista kysyä, kuvaavatko perinteiset demografiset siirtymät enää niinkään oleellisesti aikuisuuteen siirtymistä? Pyysin opiskelijoitani eräällä kurssilla kirjoittamaan tästä aiheesta oppimispäiväkirjaan. Eräs opiskelija totesi minusta asian hyvin: hän kuvaili, miten perinteiset siirtymät ovat hänen mielestään auttamattoman vanhentuneita ja hyvin konservatiivisia. Hänestä tuntuu kummalliselta asettaa aikuisuuteen tiettyjä "ehtoja", joiden saavuttamista yhteiskunnan rakenteet ja sosiaaliturva tukevat aina vaan vähemmän. Väitöstutkimukseni tulokset tukevat, ainakin osin, kyseisen opiskelijan näkemystä. Tulokset osoittivat, että useissa Euroopan maissa aikuisuuteen siirtymistä ei välttämättä määritäkään jokin tietty siirtymä.

Tätä voidaan selittää ensinnäkin sillä, että useat nuoret aikuiset näkevät, että siirtymät eivät enää ole vain kerran tapahtuvia, vaan niitä tehdään, ja uudelleen tehdään. Esimerkiksi tutkinnon suorittamisen jälkeen siirrytään työmarkkinoille, mutta tämän jälkeen paluu takaisin koulunpenkille on yhä tyypillisempää.Yhtä lailla paluumuutot lapsuudenkotiin ovat monen nuoren aikuisen toimintatapoja. Näille "jojoilijoille" tietyn siirtymän määrittäminen aikuisuuden merkiksi saattaa siten olla vaikeaa. (Esim. Biggart \& Walther 2006; Flatau, James, Watson, Wood \& Hendershott 2007; Turcotte 2007; ks. myös Shanahan 2000.)

Toinen selitys liittyy yksilöllistymisen lisääntymiseen. Yksilöllä on yhä enem- män valinnanvapautta sen suhteen, miten ja millaisia valintoja aikuistumiseen siirtyessään tekee. (Esim. Beck \& Beck-Gernsheim 2001; Corijn 2001.) Samoin omaa päätäntävaltaa on luvallista käyttää yhä enemmän myös sen suhteen, missä järjestyksessä siirtymät suorittaa vai suorittaako niitä ollenkaan. Rooliodotukset ovat siten monissa maissa hälvenneet. Nopeasti muuttuvassa maailmassa, ja erityisesti vuonna 2008 alkaneen talouslaman seurauksena, on kuitenkin kovin vaikea ennustaa valintojen seurauksia. Tämä onkin vaikuttanut nuorten aikuisten käyttäytymiseen, ja erilaisia "selviytymisstrategioita" on kehitelty (esim. Goldscheider, Thornton \& Young-DeMarco 1993; Blossfeld 2000; Billari \& Liefbroer 2010). Esimerkiksi opiskelijat saattavat lykätä valmistumistaan, jos töitä ei ole näköpiirissä, sillä opiskelija-status näyttää paremmalta kuin työtön. Avoliiton yleistymisen voi myös omalla tavallaan nähdä ilmentävän eräänlaista "katsotaan miten käy" -strategiaa.

Jos perinteiset, demografiset siirtymät aikuisuuteen eivät enää nykymaailmassa olisi valideja, mitä niiden tilalle sitten tulisi? On esimerkiksi esitetty, että avoliitto voisi korvata avioliiton aikuisuuteen siirtymisen merkkinä. Avoliitto onkin jo nykyään monissa maissa tyypillisempi parisuhteen muoto kuin avioliitto. (Ks. esim. Guzzo 2014; Settersten \& Ray 2010; OECD Family Database 2016). Myös lapsia saadaan yhtä lailla avo- kuin avioliitoissa, usein avoliitoissa jopa useammin. Toki Euroopan heterogeenisyys näkyy tässäkin kysymyksessä: tietyissä maissa, kuten Puolassa, erityisesti kulttuuriin ja uskontoon liittyvät perinteet pitävät avio- 
liittoinstituutin voimissaan (Mynarska, Baranowska-Rataj \& Matysiak 2014).

Demografisten siirtymien rinnalle tai tilalle on kuitenkin ehdotettu myös täysin muunlaisia aikuisuuteen siirtymisen markkereita. Eri maissa määrittelyt ovat erilaisia. Erityisesti amerikkalaisessa tutkimusperinteessä on korostettu viimeisten viidentoista, kahdenkymmenen vuoden ajan yksilöllisten siirtymien perään aikuisuuteen siirtymisestä puhuttaessa (esim. Arnett 1998; 2001). Aihepiirin tunnetuimmissa tutkimuksissa vastaajia on pyydetty määrittämään muutamien kymmenien väittämien pituisesta listasta ne tekijät, jotka määrittävät aikuisuutta. Valinnanvaraa on siis paljon, ja väittämät monenmoisia: esimerkiksi käyttäytymistapoihin liittyviä ja aikuisuutta määrittäviä väittämiä ovat muun muassa humalassa ajamisen välttäminen tai pikkurikosten, kuten myymälävarkauksien ja vandalismin, välttäminen $\mathrm{ja}$ biologisiin seikkoihin liittyvät väittämät kuten täyteen pituuteen kasvaminen. Tulosten mukaan keskeisimmiksi aikuisuutta määritteleviksi tekijöiksi nousevat kuitenkin kyky huolehtia itsestään, kyky tehdä itsenäisiä päätöksiä ja taloudellinen itsenäisyys.

Eurooppalaisessa tutkimusperinteessä on puolestaan keskitytty pääasiassa demografisiin, perinteisiin siirtymiin (esim. Buchmann \& Kriesi 2011). Kiinnostava jatkotutkimusaihe olisikin pohtia aikuistumiseen siirtymistä muistakin näkökulmista ja saada kulttuuristen vaikutteiden rooli myös näkyviin. On vaikea uskoa, että missään päin Eurooppaa taito välttää humalassa autolla ajamista nousisi aikuisuutta määrittäväksi tekijäksi, mutta itsenäisyys, olkoon se sitten taloudellista itsenäisyyttä tai kykyä ja mahdollisuutta tehdä itsenäisiä päätöksiä, voisi hyvin tällainen olla. Tietyissä eurooppalaisissa kulttuureissa asuntolainan nostaminen voisi varmasti nousta keskeiseksi aikuisuutta kuvaavaksi tekijäksi. Kovin maallinen huomio tähän liittyen olisi se, että asuntolaina sitoo kumppanit yhteen tiukemmin kuin avioliitto.

Palatakseni vielä omaan aikuisuuteen siirtymääni, voin todeta, että noudatin siinä pitkälti kulttuurisia ja kovin perinteisiä normeja. Muutin pois kotoa opiskeluiden takia, asuin ensin yksin, sitten muutaman vuoden avoliitossa. Avioliiton solmimisen jälkeen syntyi poikamme. Olen siis suorittanut kaikki perinteiset, demografiset aikuisuuteen siirtymisen siirtymät. Suomalaiset tavat käyttäytymisessäni näkyvät erityisesti siten, että muutin kotoa yksin vuokraasuntoon, tein töitä opintojen ohella ja valmistumisen jälkeen minusta tuli asuntovelallinen. Nykyaikaisen minusta puolestaan tekee se, että ensimmäisestä viimeisen siirtymän suorittamiseen minulla meni aikaa 14 vuotta. En ehkä kuvaisi, että käytin aikaa itse-etsiskelyyn, niin kuin nykyään usein sanotaan (esim. Ravn 2005), mutta elämästä nauttiminen ja matkustaminen olivat noina vuosina elämässäni läsnä. Aikuisuuteen siirtymisestä on tullut nykymaailmassa tyypillisesti pitkä ja yksilöllinen prosessi. Se myös tapahtuu kokonaisuudessaan aiempaa myöhemmin.

Aikuisuuteen siirtymisen myöhentyminen onkin teema, josta lähes jokaisessa aihepiirin tutkimuksessa puhutaan (esim. Buchmann \& Kriesi 2011; Crawford 2010; Fagan, Kanjuo-Mrčela \& Norman 2012; Billari \& Liefbro- 
er 2010; Sobotka \& Toulemon 2008). Selityksiä aikuisuuteen siirtymisen lykkääntymiselle on löydetty niin kulttuurisista kuin rakenteellisista tekijöistä. Ihan juuri tapahtuneesta muutoksesta ei kuitenkaan ole kyse, sillä kulttuurinen näkökulma ammentaa toisen demografisen siirtymän teoriasta, jonka alku paikantuu jo 1960-luvulle (esim. van de Kaa 2002; Lesthaeghe 2010). Teoria painottaa arvojen ja normien muutoksen keskeisyyttä ja sitä, kuinka yksilöllistyminen ja valinnanvapaus elämäntyyleissä ovat lisääntyneet ja kuinka normatiiviset ikärajat ja rooliodotukset rajoittavat aiempaa vähemmän. Viime aikoina rakenteellisilla tekijöillä on puolestaan ollut merkittävä vaikutuksensa siihen, miten sujuvaa tai eisujuvaa aikuisuuteen siirtyminen on. Institutionaaliset järjestelmät, kuten hyvinvointivaltio tai koulutusjärjestelmä, ovat kanavoineet epävarmuuden vaikutuksia eri yhteiskunnissa eri tavoin.

Jos aikuisuutta kuvaavien, perinteisten siirtymien voi nähdä ainakin jossain määrin hämärtyneen, voi ikänormien merkityksen varmasti sanoa heikentyneen (ks. esim. Furstenberg, Rumbaut \& Settersten 2008; Liefbroer 2009). Myös tässä näkökulmassa perinteistä aikuisuuteen siirtymistä ilmentäisi se, että yksilö nähdään aikuisena, kun hän on täyttänyt 18 vuotta. Silloin nuoresta toki tulee monessa maassa lain edessä täysi-ikäinen oikeuksineen ja velvollisuuksineen. Kjell Westö (2006) kuvaa romaanissaan Missä kuljimme kerran itsenäisen Suomen alkutaipaleelta sitä, miten 18 vuoden ikä teki nuoresta miehen. Kirjassa työläispoika Allu kirjoittaa ystävälleen Kaitsulle kirjeen ja kertoo seuraavaa: "Kohta synttärit mutta silloin me ollaan jo merellä. Huikka ja
Jaska sanoo, että eka satamassa johon me tullaan sitten kun mä olen kahdeksantoista, ne vie minut kaupungille ja tekee minusta miehen." Kyseistä määrittelyä aikuisuudesta esiintynee toki edelleen.

Ajatus 18 vuoden maagisesta iästä on toki siis säilynyt. Aikuiseksi minäkin taisin itseni kuvitella 18-vuotispäivänäni. Jos asiaa olisi tuolloin kysynyt vanhemmiltani, he tuskin olisivat märitelleet minut aikuiseksi käyttäytymiseni pohjalta. Kiinnostavaa on, että 18 vuoden iän merkitys aikuisuuden markkerina on edelleen voimissaan: esimerkiksi Helsingin Sanomien (2015) kolumnissa muutaman vuoden takaa toimittaja aloittaa juttunsa toteamalla "Olen 31-vuotias ja ollut nyt aikuinen 13 vuotta". Huhtikuussa 2016 Helsingin Sanomien kuukausiliitteen kannessa komeili turkulainen laulaja Robin. Otsikko lehden kannessa oli "Teinitähti Robin täyttää kesällä 18, ja hänestä tulee aikuinen".

Kyseiset melko varhaista aikuistumista kuvaavat iät ovat kovin ristiriitaisia edellä kuvatun yleisen näkemyksen kanssa siitä, että aikuisen status saavutettaisiin myöhään. Tietyissä tutkimuksissa tätä näkökulmaa on lähdetty pohtimaan siitä ajatuksesta, että nuoruudesta ei siirryttäisikään suoraan aikuisuuteen, vaan ikävuodet 18 vuodesta 25 vuoteen on nähty omaksi elämänvaiheekseen, jossa yksilö ei ole enää nuori, muttei vielä aikuinenkaan (esim. Arnett 1998; 2000). Tätä ajanjaksoa kutsutaan englanninkielessä termillä "emerging adulthood", joka on suomennettu tyypillisimmin muotoutuvaksi aikuisuudeksi. Käsite on hyvin kiistelty ja kritisoitu (esim. Côté 2014), mutta sillä on myös vankka kannattajajoukkonsa. 
Tutkimukseni tulosten mukaan on kuitenkin kiistatonta, että aikuisuuteen siirrytään nykyään myöhään. Tosin taas kerran todettakoon, että erot eri Euroopan maiden välillä ovat suuria. Eurooppa näyttäytyy yhteneväisimmältä silloin, kun tarkastellaan, milloin ensimmäinen lapsi syntyy. Keski-ikä on 28,5 vuotta ja vaihteluväli tarkasteltavien maiden välillä 4,8 vuotta. Suurimmat erot Euroopan maiden välillä havaitaan puolestaan silloin, kun verrataan lapsuudenkodista muuton ajankohtaa: se tapahtuu Ruotsissa keskimäärin 19,7 vuoden iässä, Slovakiassa vasta keskimäärin 30,9-vuotiaana. Ero on melkoinen.

Myöhäinen siirtymä aikuisuuteen on erityisen kiinnostava sosiaalipoliittisesti tarkasteltuna. Pidentyneet koulutusurat vaikuttavat siihen, että työelämään siirrytään myöhemmin. Samalla henkilöistä tulee veronmaksajia myöhemmin. Lapsuudenkodissa asuminen vaikuttaa siihen, että puolison kanssa muutetaan yhteen myöhemmin, millä puolestaan voi olla vaikutuksensa siihen, että lapsetkin hankitaan myöhemmin. Vaikeudet tulla raskaaksi taasen lisääntyvät iän myötä, ja iäkkäinä esikoislapsensa saaville jää rajallisesti aikaa perhekoon kasvattamiseen. Tällä on vaikutuksensa huoltosuhteeseen.

Siirtymä aikuisuuteen tapahtuu nykyään aivan eri olosuhteissa kuin silloin, kun järjestelmää sen eri vaiheiden tukemiseksi kehitettiin. Toki järjestelmätkin ovat muuttuneet ja muuttuvat koko ajan, mutta syytä on kuitenkin pohtia, miten onnistuneesti yhteiskunnan rakenteet tukevat yksilöä nykyisissä elämänvaiheissa. Opiskelun ja perheelämän tai opiskelun ja työelämän yh- teensovittaminen ovat ainakin usein haastavia, vaikka esimerkiksi opiskeleva ja työssäkäyvä nuori on nykyään jopa melkein ennemmin sääntö kuin poikkeus. Toisissa Euroopan maissa on kuitenkin onnistuttu muita paremmin nuorten aikuisten aikuisuuteen siirtymisen tukemisessa.

Hyväksi koettujen käytäntöjen jakaminen Euroopan maiden välillä olisikin ehdottomasti asia, mitä kannattaisi vastaisuudessa enemmän harrastaa. Esimerkiksi asuntopolitiikkaan liittyen Irlannissa ja Espanjassa tyhïï, pankkien omistamia kiinteistöä on ohjattu sosiaalisen asumiseen (Pittini, Ghekière, Dijol \& Kiss 2015) - voisiko samaa käytäntöä toteuttaa muuallakin? Suomessa puolestaan on ryhdytty Hollannista saadun idean mukaan kokeilemaan uutta asumisen mallia, jossa nuorelle tarjotaan samassa paketissa edullinen vuokra-asunto ja osa-aikainen työ naapuruston hyväksi (Helsingin Sanomat 2017). Helsingin Kannelmäessä asuu siten nyt pieni joukko nuoria, jotka maksavat asunnosta 400 euroa kuussa ja jotka ovat sitoutuneet työskentelemään parikymmentä tuntia kuukaudessa yhteisön hyväksi. Palkkaa työstä maksetaan 250 euroa. Ruotsalaiset puolestaan osaavat varmasti tehdä jotain oikein, jos mietitään perhepoliittisia asioita: naisten työllisyysaste on Euroopan korkeimpia, mutta siitä huolimatta myös syntyvyys on korkealla tasolla.Vanhempainvapaiden kiintiöimisessä Ruotsissa ollaan myös huomattavasti monia muita maita edellä. (Bonoli 2007; ks. myös Goldscheider, Bernhardt \& Brandén 2013.) Tämän kirjoituksen suomalaiset lukijat eivät tästä lauseesta varmasti pidä, mutta pitäisikö Ruotsista kuitenkin ottaa mallia? 
Väitöstutkimukseni tutkimuskysymykset ovat pitkälti rakentuneet edellä kuvaamani pohjalle; aikuisuuden määrittelyyn, aikuisuuteen siirtymisen ikään ja siihen, että aikuisuuteen siirrytään myöhään. Kahdenkymmenen Euroopan maan vertailu osoittaa selkeästi, että Eurooppa on kovin heterogeeninen, kun asiaa tarkastellaan aikuisuuteen siirtymisen valossa. Tutkimuksen tulokset osoittavat, että siirtymä aikuisuuteen eroaa merkittävästi Euroopan maiden välillä, mutta tietyissä maissa näkemykset ja toimintatavat muistuttavat toisiaan.

Näkökulmasta riippumatta yhteneväisiä piirteitä on havaittavissa Pohjoismaiden, Suomen, Ruotsin, Norjan ja osin myös Tanskan, välillä.Tämän lisäksi ehkä hieman yllättävän parivaljakon muodostavat Portugali ja Bulgaria. Näiden maiden nuorten aikuisten ajatuksissa ja käyttäytymisessä on löydettävissä yhteneväisyyttä.

Kuitenkaan ylipäänsä se, että maiden välillä ilmenee eroja ja se, että analyysien perusteella muodostetut maaryhmittymät eroavat toisistaan, ei ole yllätys. Kansalliset erot eivät ole kadonneet Euroopan maiden väliltä globalisaation myötä. Tutkimuksessa havaittavat selkeät erot eri maiden välillä antavat aiheen epäillä, että eurooppalaisten nuorten siirtymät aikuisuuteen olisivat aivan lähitulevaisuudessaankaan samanlaisia eri maissa. Tämä näkökulma tuntuu poliittisesta päätöksenteosta EU-tasolla kuitenkin usein unohtuvan. Yhteisiä tulevaisuuden suuntaviivojen usein hahmotetaan, mutta niiden toteuttamisen realistisuudesta voi olla monta mieltä.

\section{VIITTEET}

1 Kirjoitus perustuu Turun yliopistossa 17.3.2017 tarkastetun sosiaalipolitiikan väitöskirjan lectio praecursoriaan.

\section{KIRJALlisuUS}

Arnett, Jeffrey Jensen (2001) Conceptions of the Transition to Adulthood: Perspectives from Adolescence through Midlife. Journal of Adult Development 8 (2), 133-143. https://doi. org/10.1023/A:1026450103225

Arnett, Jeffrey Jensen (2000) Emerging Adulthood. A Theory of Development from the Late Teens through the Twenties. American Psychologist 55 (5), 469480. https://doi.org/10.1037/0003066X.55.5.469

Arnett, Jeffrey Jensen (1998) Learning to Stand Alone:The Contemporary American Transition to Adulthood in Cultural and Historical Context. Human Development 41 (5/6), 295-315. https://doi. org/10.1159/000022591

Bambra, Clare (2007) Going beyond the three worlds of welfare capitalism: regime theory and public health research. Journal of Epidemiology \& Community Health 61 (12), 1098-1102. https://doi. org/10.1136/jech.2007.064295

Beck, Ulrich \& Beck-Gernsheim, Elisabeth (2001) Individualization. London: Sage Publications.

Biggart, Andy \& Walther, Andreas (2006) Coping with Yo-Yo-Transitions. Young Adults' Struggle for Support, between Family and State in Comparative Perspective. Teoksessa Carmen Leccardi \& Elisabetta Ruspini (toim.) A New Youth? Young People, Generations and Family Life. Aldershot: Ashgate, 41-62.

Billari, Francesco C. \& Liefbroer, Aart C. (2010) Towards a new pattern of transition to adulthood? Advances in Life Course Research 15, 59-75. https://doi. org $/ 10.1016 /$ j.alcr.2010.10.003

Blossfeld, Hans-Peter (2000) Globalization, Social Inequality, and the Role of Country-specific Institutions. Open Research Questions in a Learning Society. 
Globalife, Working Paper No. 11.

Bonoli, Giuliano (2007) Time Matters: Postindustrialization, New Social Risks, and Welfare State Adaptation in Advanced Industrial Democracies. Comparative Political Studies 40 (5), 495-520. https:// doi.org/10.1177/0010414005285755

Buchmann, Marlis C. \& Kriesi, Irene (2011) Transition to Adulthood in Europe. Annual Review of Sociology 37, 481-503. https://doi.org/10.1146/annurev-soc-081309-150212

Corijn, Martine (2001) Transition to Adulthood: Sociodemographic Factors. Teoksessa Martine Corijn \& Erik Klijzing (toim.) Transition to Adulthood in Europe. Dordrecht: Kluwer Academic Publishers, 1-25. https://doi. org/10.1007/978-94-015-9717-3_1

Côté,James E. (2014) The Dangerous Myth of Emerging Adulthood: A EvidenceBased Critique of a Flawed Developmental Theory. Applied Developmental Science 18 (4), 177-188. https://doi.org /10.1080/10888691.2014.954451

Crawford, Kate (2010) Buying In: On Adulthood and Homeownership Ideologies. Teoksessa Judith Burnett (toim.) Contemporary Adulthood. Calendars, Cartographies and Constructions. Chippenham \& Eastbourne: Palgrave Macmillan, 39-55. https://doi. org/10.1057/9780230290297_4

Esping-Andersen, Gøsta (1990) The three worlds of welfare capitalism. Cambridge: Polity Press.

Fagan, Colette \& Kanjuo-Mrčela, Aleksandra \& Norman, Helen (2012) Young Adults Navigating European Labour Markets: Old and New Social Risks and Employment Policies. Teoksessa Trudie Knijn (toim.) Work, Family Policies and Transition to Adulthood in Europe. Basingstoke: Palgrave Macmillan, 130-154. https://doi. org/10.1057/9781137284198_6

Flatau, Paul \& James, Ian \&Watson, Richard \& Wood, Gavin \& Hendershott, Patric H. (2007) Leaving the parental home in Australia over the generations: Evidence from the household, income and labour dynamics in Australia (HILDA) survey. Journal of Population Research 24 (1), 51-71. https://doi.org/10.1007/
BF03031878

Furstenberg, Frank F. Jr. \& Rumbaut, Rubén G. \& Settersten, Richard A. Jr. (2008) On the Frontier of Adulthood: Emerging Themes and New Directions. Teoksessa Richard A. Settersten Jr., Frank F. Furstenberg Jr. \& Rubén G. Rumbaut (toim.) On the Frontier of Adulthood. Theory, Research, and Public Policy. Chicago: The University of Chicago Press, 3-25.

Goldscheider, Frances \& Bernhardt, Eva \& Brandén, Maria (2013) Domestic gender equality and childbearing in Sweden. Demographic research 29, 1097-1126. https://doi.org/10.4054/ DemRes.2013.29.40

Goldscheider, Frances K. \& Thornton, Arland \& Young-DeMarco, Linda (1993) A Portrait of the Nestleaving Process in Early Adulthood. Demography 30 (4), 683-699. https:// doi.org/10.2307/2061813

Guzzo, Karen Benjamin (2014) Trends in Cohabitation Outcomes: Compositional Changes and Engagement Among Never-Married Young Adults. Journal of Marriage and Family 76 (4), 826-842. https://doi.org/10.1111/jomf.12123

Helsingin Sanomat (2017) Naapuriavulla halpaan kotiin. 1.12.2017.

Helsingin Sanomat (2016) Poplaulajan koulupäivä. Kuukausiliite 4/2016.

Helsingin Sanomat (2015) Epäluuloiset itkeskelijät. 8.11.2015.

van de Kaa, Dirk J. (2002) The Idea of Second Demographic Transition in Industrialized Countries. Paper presented at the Sixth Welfare Policy Seminar of the $\mathrm{Na}-$ tional Institute of Population and Social Security. Tokyo, Japan.

Lesthaeghe, Ron (2010) The Unfolding Story of the Second Demographic Transition. Paper presented at the Conference on "Fertility in the History of the 20th Century - Trends, Theories, Public Discourses, and Policies." January 21-23, 2010. https://doi.org/10.1111/j.17284457.2010.00328.x

Liefbroer, Aart C. (2009) From Youth to Adulthood: Understanding Changing Patterns of Family Formation from a Life Course Perspective. Teoksessa Walther R. Heinz, Ansgar Weymann \& Jo- 
hannes Huinink (toim.) The Life Course Reader. Individuals and Societies Across Time. Frankfurt: Campus Verlag, 311337

Mynarska, Monika \& Baranowska-Rataj, Anna \& Matysiak, Anna (2014) Free to stay, free to leave: Insights from Poland into the meaning of cohabitation. Demographic Research 31, 1107-1136. https://doi.org/10.4054/ DemRes.2014.31.36

Pittini, Alice \& Ghekière, Laurent \& Dijol, Julien \& Kiss, Igor (2015) The State of Housing in the EU 2015. A Housing Europe Review. http://www.housingeurope.eu/resource-468/the-state-of-housing-in-the-eu-2015. Luettu 27.6.2016.

Ravn, Malin Noem (2005) A Matter of Free Choice? Some structural and cultural influences on the decision to have or not to have children in Norway. Teoksessa Carrie. B. Douglass (toim.) Barren States: The population Implosion in Europe. Oxford and New York: Berg Publishers, 29-47.

Settersten, Richard A. Jr. \& Ray, Barbara (2010) What's Going on with Young People Today? The Long and Twisting Path to Adulthood. The Future of Children 20 (1), 19-41. https://doi. org/10.1353/foc. 0.0044
Shanahan, Michael J. (2000) Pathways to Adulthood in Changing Societies: Variability and Mechanisms in Life Course Perspective. Annual Review of Sociology 26, 667-692. https://doi.org/10.1146/ annurev.soc.26.1.667

Sobotka, Tomáš \& Toulemon, Laurent (2008) Overview Chapter 4: Changing Family and Partnership Behaviour: Common Trends and Persistent Diversity across Europe. Demographic Research 19 (3, special collection), 85-138. https:// doi.org/10.4054/DemRes.2008.19.6

Turcotte, Martin (2007) Staying at home longer to become a homeowners? Canadian Social Trends 84, 32-36.

Westö, Kjell (2009) Älä käy yöhön yksin. Keuruu: Otavan Kirjapaino Oy.

Westö, Kjell (2006) Missä kuljimme kerran. Keuruu: Otavan Kirjapaino Oy. 